\title{
A case series of Pyridoxine Resistant Classical Homocystinuria
}

\author{
Imalke Kankananarachchi ${ }^{1}$, Thilina Madushanka Munasinghe ${ }^{2}$, Nayana Liyanarachchi ${ }^{1}$, Sujeewa Amarasena
}

${ }^{1}$ Faculty of Medicine, University of Ruhuna, ${ }^{2}$ Teaching Hospital Karapitiya

\section{Abstract}

Homocystinuria is an autosomal recessive disorder with the prevalence of 1;200000. It is due to the defect in the Methionine metabolism which results in accumulation of Homocysteine in the body. We report a series of patients with Homocystinuria followed up at university paediatric clinic Teaching Hospital Karapitiya. There were four children with Homocystinuria from 7 to 18 years, of them, 2 were males. None of them were born to consanguineous parents and two were siblings. The age at diagnosis ranged between 6 to 17 years. All children had delayed cognitive development with the IQ level between 40-77. The condition was suspected with the onset of opthalmic manifestations such as Ectopia lentis glaucoma and ptosis. Marfanoid body habitus (tall stature, high arch palate and arachnodactyly) and scoliosis were present in all four children. Three children had low bone mineral density and 2 of them had fractures. None of them had thromboembolic events. Serum Homocysteine and Methionine levels were high, ranged 145$373 \mu \mathrm{mol} / \mathrm{L}$ (4.6-8.1) and 79-177 $\mu \mathrm{mol} / \mathrm{L}$ (6-60) respectively. All had normal vitamin B12 levels between 150.0 and 216.0 $\mathrm{pmol} / \mathrm{L}$

It is well known that early detection and initiation of treatment would prevent most of the complications in Homocystinuria. However, in this case series, all children were diagnosed later. Therefore, it is important to suspect the condition in children with intellectual impairment, visual defects and marfanoid body habitus.

Copyright: This is an open-access article distributed under the terms of the Creative Commons Attribution License, which permits unrestricted use, distribution, and reproduction in any medium, provided the original author and source are credited (CC BY 4.0)

\section{https://orcid.org/0000-0002-9351-2966}

\section{Introduction}

Homocystinuria is a rare, inherited metabolic disorder of the methionine metabolism (1). Accumulation of Homocystein in, brain, blood vessels, bones and eyes, is responsible for the clinical phenotype(1). The worldwide prevalence of Homocystinuria varies between $1 ; 50,000$ to $1 ; 200,000$ (2) We report four children with homocystinuria who are being followed up at Teaching Hospital, Karapitiya. Though the first line treatment for Homocystinuria is Pyridoxine, all of them were resistant to the standard treatment.

\section{Case 01}

A 17-year-old girl was referred by the ophthalmologist for further evaluation of downward lense subluxation and glaucoma. Since early childhood she had global developmental delay and stopped schooling at grade 8 . Examination revealed marfanoid body habitus and severe

degree of scoliosis. Her height was at 95th centile and the Intelligent quotion (IQ) score was 43.
Investigations showed elevated Homocysteine and Methionine with normal levels of vitamin B12 suggestive of Homocystinuria due to Cystathionine beta-synthase deficiency. Dual energy X-ray absorptiometry (DXA) scan revealed low bone mineral density (BMD). She was commenced on high doses of Pyridoxine and methionine restricted diets, however, there was no improvement of her biochemistry.

\section{Case 02}

A 10 year old boy presents with poor academic performances and visual disturbances. He was the second child born to non-consanguineous parents with one affected elder sibling with homocystinuria. He had had a fracture radius at the age of 5 years following minor trauma. He was followed up at child psychiatry clinic for attention deficit hyperactive (ADHD) disorder since 7 years of age. His IQ score was 70 . Examination didn't reveal any marfanoid body habitus and his height was at 50th centile. Investigations showed high homocysteine and Methionine levels with normal B12 suggestive of $\mathrm{CH}$. His DXA scan showed low BMD. Though, he was started on high dose Pyridoxine and 
methionine restricted diet, the expected biochemical response was not seen.

\section{Case 03}

An 11-year-old girl was referred by the ophthalmologist for further evaluation of glaucoma and ectopia lentis. She was tall for her age and had marfanoid body habitus. She had global developmental delay and she attends to a special school. Her IQ score was 54. Investigations revealed elevated Methionine and Homocystein with normal B12 levels suggestive of $\mathrm{CH}$. Her DXA scan showed low BMD. There was no improvement in her serum Homocystein level following Pyridoxine treatment.

\section{Case 04}

A seven-year-old child who has had global developmental delay presents with impaired vision. He was found to have ectopia lentis, proptosis and marfanoid body habitus. He had a fracture tibia at the age of four years. He was behind his peers at school and the IQ score was 40. Investigation findings were compatible with a case of $\mathrm{CH}$ and $\mathrm{BMD}$ was low in DXA scan. He was commenced on high dose Pyridoxine therapy and methionine restricted diet, for which there was no biochemical improvement.

Table 1: Biochemical values of Patients with Homocystinuria

Case

Homocystein

$(4.6-8.1 \mu \mathrm{mol} / \mathrm{L})$

373

145

565
Methionine

B12 (140-650 pmol/L)

$(6-60 \mu \mathrm{mol} / \mathrm{L})$

\begin{tabular}{l|ccc}
01 & 318 & 177 & 216 \\
02 & 373 & 79 & 160 \\
03 & 145 & 99 & 210 \\
04 & 565 & 109 & 203
\end{tabular}




\section{Discussion}

Homocysteine is produced by the Cystathionine betasynthase (CBS) enzyme as an intermediate product of methionine metabolism. In the absence of CBS enzyme, Homocystein accumulates in different organs in the body such as brain, eye, blood vessels and bones resulting multisystem disease (1).

The clinical presentation of $\mathrm{CH}$ varies depends on the severity of the enzyme deficiency and milder forms might not present until they get thromboembolic events in adolescence (3). However, all these children had severe multisystem involvement since early childhood. In this case series the commonest reason to suspect the condition was ophthalmic manifestations and marfanoid body habitus.

The ophthalmologic manifestations seen in $\mathrm{CH}$ are ectopia lentis, astigmatism Glaucoma, Cataract, Retinal detachment and Optic atrophy (4). In this case series all four children had ectopia lentis and the two of them had glaucoma. Moreover, all these patients had low IQ (40-77) and neuropsychiatric manifestations. All these children had low bone mineral density and two of them had fractures.
Though, none of them had thromboembolic manifestations up to now they are at risk of developing such events in future.

The worldwide prevalence of pyridoxine responsiveness in CBS deficiency is $50 \%$, however, all these patients were Pyridoxine resistant (3). For late-diagnosed patients the target Homocystein level should be $<100 \mu \mathrm{mol} / \mathrm{L}$ and pyridoxine resistant patients need Betaine therapy, which is not available in Sri Lanka (5).

\section{Conclusion}

In the absence of new-born screening programme to detect Homocystinuria, in Sri Lanka, patients with homocystinuria have developed major complications at the time of diagnosis. However, it is important to consider Homocystinuria in children with marfanoid body habitus, neuro-psychiatric manifestations and fractures. Moreover, it is important to make Betaine available in Sri Lanka to treat these children with pyridoxine resistant Homocystinuria.

\section{References}

1. Mudd SH, Skovby F, Levy HL, Pettigrew KD, Wilcken B, Pyeritz RE, Andria G, Boers GH, Bromberg IL, Cerone R, Fowler B. The natural history of homocystinuria due to cystathionine $\beta$-synthase deficiency. American journal of human genetics. 1985 Jan;37(1):1.

2. García-Jiménez MC, Baldellou A, García-Silva MT, Dalmau-Serra J, García-Cazorla A, Gómez-López L, Giner CP, Luengo OA, Peña LQ, Couce ML, Martínez-Pardo M. Epidemiological study of the metabolic diseases with homocystinuria in Spain. In Anales de pediatria (Barcelona, Spain: 2003) 2012 Mar (Vol. 76, No. 3, pp. 133-139).

3. Morris AA, Kožich V, Santra S, Andria G, Ben-Omran TI, Chakrapani AB, Crushell E, Henderson MJ, Hochuli M, Huemer M, Janssen MC. Guidelines for the diagnosis and management of cystathionine beta-synthase deficiency. Journal of inherited metabolic disease. 2017 Jan 1;40(1):49-74.

4. Mulvihill, A., Yap, S., O'Keefe, M., Howard, P.M. and Naughten, E.R., 2001. Ocular findings among patients with latediagnosed or poorly controlled homocystinuria compared with a screened, well-controlled population. Journal of American Association for Pediatric Ophthalmology and Strabismus, 5(5), pp.311-315.

5. Lawson-Yuen A, Levy HL. The use of betaine in the treatment of elevated homocysteine. Molecular genetics and metabolism. 2006 Jul 31;88(3):201-7. 